\title{
Communities of Practice
}

\section{A Research Paradigm for the Mixed Methods Approach}

\author{
Martyn Denscombe \\ De Montfort University, Leicester, United Kingdom
}

\begin{abstract}
The mixed methods approach has emerged as a "third paradigm" for social research. It has developed a platform of ideas and practices that are credible and distinctive and that mark the approach out as a viable alternative to quantitative and qualitative paradigms. However, there are also a number of variations and inconsistencies within the mixed methods approach that should not be ignored. This article argues the need for a vision of research paradigm that accommodates such variations and inconsistencies. It is argued that the use of "communities of practice" as the basis for such a research paradigm is (a) consistent with the pragmatist underpinnings of the mixed methods approach, (b) accommodates a level of diversity, and (c) has good potential for understanding the methodological choices made by those conducting mixed methods research.
\end{abstract}

Keywords: communities of practice; mixed methods; pragmatism; research paradigm

\section{Introduction}

Mixed methods research has developed rapidly in recent years. Championed by writers such as John Creswell, Abbas Tashakkori, Burke Johnson, Anthony Onwuegbuzie, Jennifer Greene, Charles Teddlie, and David Morgan, the mixed methods approach has emerged in the last decade as a research movement with a recognized name and distinct identity. It has evolved to the point where it is "increasingly articulated, attached to research practice, and recognized as the third major research approach or research paradigm" (Johnson, Onwuegbuzie, \& Turner, 2007, p. 112).

As a research paradigm, the mixed methods approach incorporates a distinct set of ideas and practices that separate the approach from the other main research paradigms. These are outlined briefly in this article. However, there are also aspects of mixed methods research on which there is a relative lack of consistency or agreement. These too are sketched out in this article. It should be emphasized though that the purpose for doing so is not to undermine the status of the mixed methods approach as a paradigm for research. Other research paradigms, subjected to detailed examination, will exhibit their own variations and inconsistencies and there should be no suggestion that just because the mixed

Author's Note: Please address correspondence to Martyn Denscombe, Department of Public Policy, De Montfort University, The Gateway, Leicester LE1 9BH, England; e-mail: md@dmu.ac.uk. 
methods approach does not achieve complete coherence and consistency it is automatically disqualified from the status of a research paradigm. The purpose instead is to draw attention to the way in which the notion of "research paradigm" might need to accommodate a level of variation and inconsistency in its ideas and practices - treating them not as some kind of aberration or short-term problem that needs to be resolved but as an ongoing and inherent feature of the paradigm itself. The purpose is to highlight the need for a notion of paradigm that can be sufficiently flexible, permeable, and multilayered to reflect the reality of social research in the 21 st century. This is where "communities of practice" come into play. It is argued that a notion of research paradigm based on communities of practice could have particular benefits in relation to the mixed methods approach through the way it is consistent with the pragmatist underpinnings of the approach, through its ability to accommodate the existence of variations and inconsistencies within the approach, and through its potential for understanding the decisions of researchers relating to their use of the mixed methods approach.

\section{Mixed Methods: The Third Paradigm for Research}

The origins of mixed methods research can be traced to its use among fieldwork sociologists and cultural anthropologists early in the 20th century (Creswell, 1999, p. 458; Johnson et al., 2007, p. 113). However, those who have sought to put a chronological timeline to its evolution as a research paradigm have tended to place it against a backdrop of the "paradigm wars." Although there has not been complete unanimity about the dates, the general theme has been that an early period in which the positivist paradigm (linked with quantitative methodologies) was dominant (1950s to mid-1970s) changed to an era in which the constructivist research paradigm (linked with qualitative methodologies) became established as a viable alternative (mid-1970s to 1990s). Mixed methods, as a research paradigm, is seen as emerging from the 1990s onwards, establishing itself alongside the previous paradigms so that "we currently are in a three methodological or research paradigm world, with quantitative, qualitative, and mixed methods research all thriving and coexisting" (Johnson et al., 2007, p. 117).

The intellectual roots of the paradigm are generally traced to the early work of Campbell and Fiske (1959) on mixing methods (Collins, Onwuegbuzie, \& Sutton, 2006; Creswell, 2003; Creswell \& Plano Clark, 2007; Creswell, Tashakkori, Jensen, \& Shapley, 2003; Greene, Caracelli, \& Graham, 1989; Johnson et al., 2007). Following Campbell and Fisk's pioneering work, Webb, Campbell, Schwartz, and Sechrest (1966) and then Denzin (1970) and Jick (1979) tend to get cited in relation to developments around the notion of triangulation. Cook and Reichardt (1979) generally receive acknowledgment in connection with their consideration of the compatibility of quantitative and qualitative research, and Greene et al. (1989) herald a key point in the time line with their seminal typology of mixed methods use. Building on these foundations, "mixed methods research has evolved to the point where it is a separate methodological orientation with its own worldview, vocabulary, and techniques" (Tashakkori \& Teddlie, 2003, p. x). The distinctive nature of the mixed methods approach and the core ideas and practices on which the paradigm stands have been captured in the works of those such as Creswell (2003), Creswell and Plano Clark (2007), and 
Tashakkori and Teddlie (1998, 2003). These writers, along with others, contrast the mixed methods approach with research paradigms that have favored the use of either quantitative or qualitative methodologies, and they have argued that the defining characteristics of the mixed methods approach involve its use of

- quantitative (QUAN) and qualitative (QUAL) methods within the same research project,

- a research design that clearly specifies the sequencing and priority that is given to the QUAN and QUAL elements of data collection and analysis,

- an explicit account of the manner in which the QUAN and QUAL aspects of the research relate to each other, with heightened emphasis on the manner in which triangulation is used, and

- pragmatism as the philosophical underpinning for the research.

\section{Variations and Inconsistencies Within the Paradigm}

In the context of a new paradigm, it is hardly surprising to find a good deal of emphasis on the shared ideas and practices that exist among mixed methods researchers and the way that these distinguish the paradigm as a genuine alternative to others. In focusing on areas of consensus within the paradigm, however, there is the danger of overlooking the complexities of the situation. As Johnson et al. (2007) acknowledge, "the dividing lines are much fuzzier than typically suggested in the literature" and "positions are not nearly as 'logical' and as distinct as is frequently suggested in the literature" (p. 117). Nor should we lose sight of the fact that there are "inconsistencies in the way (that) scholars define and conceptualize mixed methods" (Tashakkori \& Creswell, 2007a, p. 3). Such variations and inconsistencies within the approach deserve consideration (Greene, 2008; Holmes, 2006) and, recognizing this point, the following discussion explores some of the variations and inconsistencies. Although there is no suggestion of providing an exhaustive list, their significance for the mixed methods approach as a paradigm should become apparent.

\section{Purposes of Mixed Methods Research}

Reviews of published mixed methods studies reveal the diversity of ways in which social researchers use mixed methods (e.g., Bryman, 2006; Greene et al., 1989; Rocco, Bliss, Gallagher, \& Perez-Prado, 2003), with Collins et al. (2006, pp. 78-79) identifying four broad rationales and 65 specific purposes existing within the extensive range of mixed methods research that they reviewed. Synthesizing the various typologies that arise from reviews of existing mixed methods research, (a) some researchers use mixed methods to improve the accuracy of their data, whereas (b) others use mixed methods to produce a more complete picture by combining information from complementary kinds of data or sources. Sometimes (c) mixed methods are used as a means of avoiding biases intrinsic to single-method approaches - as a way of compensating specific strengths and weaknesses associated with particular methods. Mixed methods have been (d) used as a way of developing the analysis and building on initial findings using contrasting kinds of data or methods. And mixed methods approaches have often been (e) used as an aid to sampling with, for example, questionnaires being used to screen potential participants for inclusion in an interview program. 


\section{Relationship Between "Quantitative" and "Qualitative" Components}

Definitions and discussions of research design within the mixed methods approach generally refer to the distinction between quantitative and qualitative methods. The distinction, however, brings with it two strands of divergence among those involved with the mixed methods approach. First, there is some difference of opinion about the "commensurability" of quantitative and qualitative methodologies. Within the mixed methods approach, there are differing views on how quantitative and qualitative elements of research should be used within a specific project and whether they can be integrated, combined, or used in tandem. For some writers the philosophical premises of quantitative and qualitative methodologies are considered to be incompatible, which leads them to advocate their use "in parallel," each playing to its respective strengths (e.g., Brewer \& Hunter, 1989; Morse, 2003). Other writers have sought to find common ground between the two alternatives and have made efforts to highlight the similarities between quantitative and qualitative approaches as a basis for combining their use (e.g., Datta, 1994; Hardy \& Bryman, 2004; Onwuegbuzie \& Leech, 2005; Pring, 2000; Reichardt \& Rallis, 1994). Second, questions have been raised about the viability of using a simple quantitativequalitative dichotomy. The point has been made on many occasions that the distinction between the notions of quantitative and qualitative is not watertight and that any simple quantitative-qualitative distinction hardly does justice to the variety of epistemological and ontological assumptions that underpin the terms (e.g., Bryman, 1988; Cook \& Reichardt, 1979; Coxon, 2005; Gorard \& Taylor, 2004; Hammersley, 1992; Lasswell, 1961).

\section{Interpretation of Pragmatism}

Pragmatism is generally regarded as the philosophical partner for the mixed methods approach. It provides a set of assumptions about knowledge and inquiry that underpins the mixed methods approach and distinguishes the approach from purely quantitative approaches that are based on a philosophy of (post)positivism and from purely qualitative approaches that are based on a philosophy of interpretivism or constructivism (Johnson \& Onwuegbuzie, 2004; Maxcy, 2003; Rallis \& Rossman, 2003). However, it is possible to discern four facets of the way in which pragmatism underlies the practice of mixed methods research. These aspects of pragmatism are not necessarily mutually exclusive options. In practice there might well be a degree of overlap between them. However, the identification of four aspects of pragmatism as used within the mixed methods approach does serve to warn that the approach does not actually operate on the basis of a unitary, agreed vision of pragmatism.

On some occasions (a) pragmatism provides a fusion of approaches. Seeking to challenge what are regarded as sterile and unproductive dualisms, some mixed methods researchers favor a search for common ground-some compatibility-between the "old" philosophies of research (e.g., Datta, 1994; Maxcy, 2003; Tashakkori \& Teddlie, 1998, 2003). On other occasions (b) pragmatism provides a basis for using mixed methods approaches as a third alternative - another option open to social researchers if they decide that neither quantitative nor qualitative research alone will provide adequate findings for 
the particular piece of research they have in mind (Johnson et al., 2007; Tashakkori \& Creswell, 2007b). Contrasting with this, there are times when (c) pragmatism is treated as a new orthodoxy built on the belief that not only is it allowable to mix methods from different paradigms of research but it is also desirable to do so because good social research will almost inevitably require the use of both quantitative and qualitative research to provide an adequate answer (e.g., Greene, Benjamin, \& Goodyear, 2001; Greene, Kreider, \& Mayer, 2005; Rocco et al., 2003). And then there are occasions when (d) pragmatism is treated in the commonsense way as meaning "expedient." There is a commonsense use of the word pragmatic that implies a certain lack of principles underlying a course of action. There is the danger then that the mixed methods approach gets associated with this understanding of the word and thus comes to be regarded as an approach in which "anything goes." It should be stressed that this is not the philosophical meaning of pragmatism and it is not a meaning that should be associated with the mixed methods approach.

\section{Boundaries of the Paradigm}

The mixed methods approach does not exercise exclusive rights over the use of mixed methods in research or the use of pragmatism as the philosophical foundations for research, and there is a danger of overstating the extent to which the mixed methods approach has involved a whole new way of seeing things that combines quantitative and qualitative methodologies. Before the emergence of the mixed methods paradigm there were examples of researchers combining their methods. The Hawthorne experiments provide a classic example dating from the 1920s and 1930s (Mayo, 1933/2003; Roethlisberger \& Dickson, 1939/ 2003). Even the Chicago School studies of the same era, conventionally associated with qualitative case study research, were not averse to the use of quantitative data as a complement to the qualitative material (Hammersley, 1989; Harvey, 1987). Indeed, there is evidence to suggest that for a long time the use of mixed methods has been going on in the background without being celebrated or heralded as part of a new paradigm.

There is also evidence to suggest that many contemporary instances of combining methods take place without explicitly or formally acknowledging that the practice relates to the mixed methods approach or its practical and philosophical premises (Bryman, 2006; Gorard \& Taylor, 2004; Greene et al., 1989). Using a content analysis of findings from 232 journal articles that combined quantitative and qualitative methods, Bryman (2006) found that about $27 \%$ did not state why they had chosen a mixed methods approach. And on the basis of interviews with 20 researchers who had chosen to combine quantitative and qualitative methods in their research, Bryman (2007) concluded that "Typically... mixed methods researchers seem not to dwell on epistemological and ontological issues and exhibit a clear pragmatism in their work" (p. 17). Note here though that Bryman's use of the term pragmatism relates to expediency — not to a use of the "philosophy" of pragmatism as envisaged in the mixed methods paradigm.

At the level of theory too the case for combining quantitative and qualitative research is not unique to the mixed methods paradigm. It has been explored by a number of eminent writers on methodology (e.g., Bryman, 1988, 2004; Hammersley, 1989, 1992; Layder, 1993, 1998; Silverman, 1985, 2000) who, although they have made valuable contributions 
in their own right to a broader notion of a mixed methods strategy in social research, have not tended to feature in the narrative of its intellectual origins provided by key writers linked with the mixed methods approach.

Nor is the mixed methods paradigm alone in its use of pragmatism as its philosophical underpinning. Pragmatism provides a recurrent theme underlying forms of research that can be traced back throughout the last century through the works of symbolic interactionists such as Dewey, Mead, Blumer, and Goffman (Cherryholmes, 1992; Maxcy, 2003), and there are aspects of pragmatism involved in grounded theory, ethnomethodology, conversational analysis, and discourse analysis of people such as Glaser, Strauss, Garfinkel, Cicourel, and Foucault (Guignon, 1991; Rorty, 1982, 1991).

\section{Research Paradigms as Communities of Practice}

Drawing attention to the existence of variations and inconsistencies does not automatically invalidate the claims of the mixed methods approach to be a research paradigm. After all, there are schisms within the quantitative and qualitative approaches to research that have persisted for a considerable time without being resolved. It suggests instead that the mixed methods approach might benefit from the use of a foundation that better allows it to incorporate the variations and inconsistencies evident within the approach. Morgan's (2007) account of the evolution of the mixed methods approach is useful in this context. He reminds us that the term research paradigm has more than one meaning. Indeed, Masterman (1970) identified as many as 22 uses of the term contained within the original version of "The Structure of Scientific Revolutions," and Kuhn (1962/1970) himself acknowledges that there are four main meanings of the term research paradigm. The interesting point that Morgan makes is that social researchers have focused almost exclusively on just one of those versions: the version of paradigms as epistemological stances. Morgan makes the case that the focus of attention on this version of research paradigm both caused and reflected a shift in the nature of methodological debate from the level of practice or outcomes to that of metaphysics. Paradigms, in this sense, concern higher level belief systems and the way these link with research questions. They concern questions about the nature of reality and fundamental issues about the knowability of this reality-about ontology and epistemology. Morgan's argument is that this shift in the grounds of debate reflected a growing assertiveness on the part of qualitative researchers concerning the legitimacy of their kind of research. By shifting the debate to a metaphysical level, qualitative researchers became able to compete with quantitative researchers on a more or less even footing with respect to their knowledge claims and thus managed to challenge the dominance of the quantitative research that had characterized the 1960s and 1970s. During the 1980s and 1990s, says Morgan, "the movement of Qualitative Research from a relatively marginal position to essential equality with Quantitative Research amounts to a clear shift in the historical pattern" (p. 55). This represents a paradigm change that was driven by the "dedicated efforts of advocates" but crucially one that was enabled by shifting the methodological debate from the level of research practice to the level of theoretical principles. 
As Morgan points out, though, Kuhn actually expressed a preference for a version of research paradigms much more clearly rooted in research practice and research communities than in the realms of debate surrounding ontology and epistemology. He saw such paradigms as being characterized by four things (Kuhn, 1962/1970, pp. 176-183). First, they center on a specific problem or set of problems that are regarded as particularly significant in relation to the advancement of knowledge. Second, they are about shared practice. Such paradigms involve a shared understanding about which research techniques are appropriate for investigating that issue. Third, these paradigms involve a sense of shared identity. Based to some extent on the specialist area of research, this shared identity is reinforced through the processes of information exchange they use (specialist publications and conferences) and through the interpersonal networks that practitioners establish in relation to their area of research. And fourth, these paradigms operate through groups of practitioners operating in research communities. These research communities, Kuhn argues, can exist at a number of levels. At the highest level, such a community could incorporate all those engaged in scientific research. At a lower level, there are communities operating at the level of subject disciplines, and within these there are communities linked to particular areas and subdisciplines. Communities, in other words, can exist at different levels and will vary in size. They can be quite small, particularly in the case of cutting-edge research, and membership of one community does not automatically exclude membership of another. Kuhn points to "communities of perhaps one hundred members, occasionally significantly fewer. Usually individual scientists, particularly the ablest, will belong to several such groups either simultaneously or in succession" (Kuhn, 1962/1970, p. 178).

The notion of research paradigms based on such smaller communities is markedly different from the notion of paradigms linked to overarching grand epistemological paradigms. The communities are multilevel, overlapping, and potentially fluid. Viewed in this way, research paradigms resonate closely with the concept of "communities of practice." This concept, although it was derived from social learning theory and developed largely in connection with the management of knowledge in formal organizations, maps neatly onto the practices of researchers within academic institutions and research organizations.

The term communities of practice is generally attributed to Lave and Wenger (1991) and the later work of Wenger (see Wenger, 1998a, 1998b; Wenger \& Snyder, 2000). At the heart of the notion of communities of practice lies a key problematic: the acquisition of knowledge. It is axiomatic for the originators of the term that learning has a social and communal facet to it that exists quite distinct from learning at an individual and personal level. Learning, from this perspective, is a collective activity. The knowledge that is acquired is knowledge produced within the group - it is shared knowledge. And the process of acquiring knowledge is social-it is learned through participation within the group and through the adoption of shared practices.

The social learning theory that underpins the notion of communities of practice emphasizes the role of informal groupings initiated in response to the need to deal with a shared problem. Compared with formal groups created within organizations whose structure, tasks, and identity are established through functional lines and status hierarchies, communities of practice hinge on the fact that they can and do transcend boundaries of departments, organizations, locations, and seniority. It is crucial to the whole idea of communities of practice 
that they come into existence through the need to collaborate with those who face similar problems or issues for which new knowledge is required. This quest involves contact with people who may be in other departments, organizations, or places. Indeed, it is quite feasible for there to be virtual communities based entirely on communication technologies that eliminate the need for face-to-face contact. What brings them together as a community, though, is that they share a common purpose (Johnson-Lenz \& Johnson-Lenz, 1999) and the common purpose reflects a need to know what each other knows (Brown, 1999). So as Mitchell, Wood, and Young (2001) emphasize, it is the purpose of the communication rather than its form that is the important thing: "Members (may) interact in different ways and focus on different goals. Nevertheless, at the core of each of these communities, members remain bound by what they do together and by what they have learnt through their mutual engagement in a range of activities" (p. 5).

This emphasis on situated learning has caused some commentators to worry about the way communities of practice might elevate practice-based knowledge above more theoretical and abstract forms of knowledge. Hammersley (2005), for example, voices such a concern in relation to educational research. He argues that if communities of practice are treated normatively as the preferred basis for the generation of knowledge there are implicit dangers for more abstract, propositional forms of knowledge of the kind associated with academic theory and university research work. If communities of practice are treated as the appropriate way in which knowledge should be developed, the critical stance of the detached observer can lose out to the practitioners' concerns with solutions to here-and-now problems. In effect, "scientific" research could be sidelined as "an artificial enterprise... necessarily producing alienated-propositional and decontextualized-knowledge which cannot but be irrelevant to educational practice" (Hammersley, 2005, p. 16). Hammersley's concern relates principally to the context of educational research in the United States and the United Kingdom at a time when there are political interests at stake that favor practicebased research. Under these circumstances, the argument is that communities of practice might have the effect of wresting control of the research agenda away from professional, academic researchers and of emphasizing the value of practical knowledge at the expense of more esoteric, long-term, theoretical knowledge. Hodkinson (2004) echoes such concerns, although in his case it is because communities of practice are seen as forming part of a "new orthodoxy" in educational research in which there is the "dominance of positivistic or empiricist views of research and the primacy of objectivist methods" (p. 23). In either case, however, the negative connotations associated with communities of practice relate to circumstances where (a) communities of practice are advocated as the preferred basis for producing research knowledge and (b) there is a fairly clear distinction between practitioners (teachers) and researchers (academics). With respect to the mixed methods approach, though, neither circumstance really applies. In the discussion of mixed methods research, communities of practice have been treated primarily as a description of how research communities operate rather than being advocated as a path that ought to be followed. And with respect to the mixed methods approach, there is no clear distinction between practitioners and researchers. The practice is the research; the research is the practice. What is being discussed in this article are communities of researchers who work within academic and research institutions for whom the distinction between practitioner knowledge and research knowledge is hard to sustain. Arguably, the two things are inseparable. 


\section{Communities of Practice and the Mixed Methods Approach}

Communities of practice meet the four criteria for a practice-based research paradigm as envisaged by Kuhn. Through their shared learning and mutual collaboration linked to a key research problem, they develop distinctive practices and languages that foster a group identity. Communities of practice also offer something of particular value to the mixed methods approach. When applied to the mixed methods approach, the existence of variations and inconsistencies within the paradigm no longer poses a critical problem. This is because communities of practice provide the basis for a research paradigm that is sufficiently flexible, permeable, and multilayered to accommodate the variety of ways in which mixed methods are used and the variety of motives researchers might have for adopting a mixed methods approach.

Initially, this is because the research paradigm comprises a conglomerate of multiple research communities rather than a monolithic entity. Within the mixed methods approach this is evident in the various subcommunities that exist along the lines of different subject areas (education, health, business, etc.), different orientations (theory, practice, policy evaluation, emancipation), different research traditions (postpositivist, constructivist, historical, comparative, etc.), and as Greene (2008) indicates, different research domains. Linked with this, the communities of practice can exist at different levels. Echoing the point made by Kuhn (1962/1970), a paradigm can exist at some very broad, overarching level, but beneath this, communities of practice can exist at a number of lower levels. These lower level research communities will have particular interests and research questions that drive them and give them a sense of communal identity, but their members can still feel an affinity with the higher level and larger research community. Despite their specific interests, they can share a broader purpose.

Second, membership of the communities of practice is open to change. The chances are that there will be some movement between communities and that researchers might well belong to more than one community at a time. And this movement need not be restricted within a particular paradigm. The communities of practice approach to research paradigms can also accommodate the possibility of permeable boundaries to the paradigm. Rather than researchers being confined to one tradition and constrained by the knowledge and skills associated with that tradition, this understanding of a research paradigm comfortably deals with the possibility that researchers might transfer allegiances or "have a foot in both camps." As Morgan observes, "for Kuhn, there is nothing about the nature of paradigms (in the sense of shared beliefs among the members of a speciality area) that inherently prevents the followers of one such paradigm from understanding the claims of another" (Morgan, 2007, p. 62).

Third, the communities of practice version of research paradigms has good potential for understanding the methodological choices made by those conducting mixed methods research. Rather than treat such decisions as purely individual or entirely rational—based solely on some objective calculation of the benefits of adopting a mixed methods approach relative to other available alternatives-it can accommodate the social factors that affect methodological decisions. And there is empirical evidence that such social factors are significant in the context of mixed methods research. As Bryman (2007) found, "the reasons 
for the difficulty of integrating quantitative and qualitative research is only partly to do with factors intrinsic to these two research strategies; it is also very influenced by the predispositions and preferences of researchers and of disciplines and funding agencies" (pp. 19-20).

With their emphasis on the social nature of knowledge acquisition, communities of practice sit comfortably with the idea that researchers' methodological decisions are influenced by predispositions and preferences. The communities of practice model is well placed to deal with the fact that decisions about the use of a mixed methods approach will be shaped by a socialization process involving the influence of peers. It can deal with the fact that researchers are likely to acquire some mind-set about which kinds of data and analysis are to be considered "preferable" and "better" than others through the way membership of different communities leads to the internalization of particular values and the inculcation of specific skill-sets.

Equally, communities of practice can accommodate the way that decisions can be shaped by peer pressure. Through peer review of academic articles and funding proposals, researchers experience constraints that can have a direct impact on their decision concerning the use of a mixed methods approach, and researchers who have regard to careers and research funding will find it hard, probably impossible, to ignore such an influence to conform to group norms.

There are circumstances, however, where methodological choices are influenced by factors external to the community of practice-and these should not be ignored. Choices are made within a social context where power can be exercised to influence decisions concerning the adoption of a mixed methods approach. Meyer (2005) offers an example of this in connection with health research in the United Kingdom. She describes how health researchers have been officially encouraged to mix their methods but in practice find that they can do so only within a postpositivist paradigm of research. The dominance of evidence-based practice and systematic reviews in the health sphere, she argues, have served to ensure that randomized controlled trials continue to be treated as the gold standard for research whether the research relates to medical interventions and effectiveness of drugs or whether it concerns health promotion of other social facets of healthcare. Giddings (2006) makes a similar point with respect to nursing research. She argues that the inclusion of qualitative research has occurred only to the extent that it meets a postpositivist research agenda in which the aim of combining the use of quantitative and qualitative methods is to get more "accurate" results, not to explore complexities and contradictions in their own right. And in the field of education there is the same kind of constraint on the choice of methodology. As Somekh (2005) has demonstrated, "educational researchers are facing increasing demands for 'hard data' generated by pseudo-positivist methods that purport to establish cause and effect between educational practice and improved test scores" (p. 8). What these examples indicate is that communities of practice do not operate in a power vacuum. Communities of practice themselves can differ in terms of their power, their influence, and their credibility, and it needs to be acknowledged that the mixed methods paradigm might not yet carry the degree of recognition or acceptability outside the realms of social research that would make it equal on its own terms with, for instance, the medical model of research. Also, communities of practice operate within a political context, which means that although they may consist of cutting-edge researchers, 
their vision of what needs to be investigated and how it should be researched might be stifled if these are perceived to threaten the interests of more powerful research communities or do not align with the interests of powerful policy makers.

\section{Conclusion}

The mixed methods approach can be seen as offering a third paradigm for social research through the way it combines quantitative and qualitative methodologies on the basis of pragmatism and a practice-driven need to mix methods. As such, it is framed by a whole variety of practical issues and demands (rather than being guided by some overarching philosophy) and, almost inevitably, this means that the manner in which the elements of quantitative and qualitative methodologies get combined is liable to be fragmented and inconsistent. And this is exactly what can be witnessed with researchers using mixed methods research for a variety of purposes and combining the quantitative and qualitative elements in differing ways. This article has outlined some of the variations and inconsistencies these entail.

Such variations and inconsistencies, it has been argued, should not be regarded as alien to the concept of paradigm nor in some sense a unique weakness of the mixed methods paradigm. The existence of variations and inconsistencies within the mixed methods approach, however, does alert us to the need to reconceptualize the notion of paradigm in a way that accords with the practice-driven nature of the approach and the increased likelihood this brings for variation and inconsistency within the paradigm. In this context, it has been argued that the notion of communities of practice might be particularly useful.

The benefits of defining research paradigms in terms of communities of practice, it needs to be stressed, have been suggested rather than demonstrated. As Kuhn (1962/1970, p. 176) acknowledged in relation to his own work, the empirical investigation of researcher communities and networking is a separate task that is far from trivial, not least in terms of its technical demands. However, bearing this caveat in mind, communities of practice would seem to be beneficial in four ways. First, they can accommodate the varieties and inconsistencies within the mixed methods approach through the flexibility they afford in terms of groupings of researchers and the way they allow the notion of paradigm to operate at different levels. Second, they can help explain why the mixed methods approach might seem more attractive to some researchers than others by taking into account the group influences on methodological choices. The choice of research methodology is seen as a reflection of factors such as career interests, funding opportunities, training, and personal skills rather than a purely "rational" choice based on the respective merits of the available alternatives. Third, communities of practice are in line with Kuhn's thinking on the nature of research paradigms as they operate in the natural sciences and they sit comfortably with Morgan's (2007) discussion of the benefits of shifting attention away from debates about paradigms at the metaphysical level (epistemology and ontology) toward debates at the level of practice and research culture. Fourth, communities of practice are consistent with pragmatism and they place special emphasis on the problem-driven nature of inquiry and learning. In the way they operate, they do not tie methodological choices to metaphysical principles (epistemology and ontology) but allow, instead, methods to be chosen in terms of their practical value for dealing with a specific research problem. 


\section{References}

Brewer, J., \& Hunter, A. (1989). Multimethod research: A synthesis of styles. Newbury Park, CA: Sage.

Brown, J. S. (1999). What is a community of practice? Retrieved August 10, 2007, from http://www.co-i-1 .com/coil/knowledge-garden/cop/definitions.shtml

Bryman, A. (1988). Quantity and quality in social research. London: Unwin Hyman.

Bryman, A. (2004). Triangulation. In M. Lewis-Beck, A. Bryman, \& T. F. Liao (Eds.), The Sage encyclopedia of social science research methods. Thousand Oaks, CA: Sage.

Bryman, A. (2006). Integrating quantitative and qualitative research: How is it done? Qualitative Research, 6(1), 97-113.

Bryman, A. (2007). Barriers to integrating quantitative and qualitative research. Journal of Mixed Methods Research, 1(1), 8-22.

Campbell, D. T., \& Fiske, D. W. (1959). Convergent and discriminant validation by the multitrait-multimethod matrix. Psychological Bulletin, 56(2), 81-105.

Cherryholmes, C. H. (1992). Notes on pragmatism and scientific realism. Educational Researcher, 14, 13-17.

Collins, K. M. T., Onwuegbuzie, A. J., \& Sutton, I. L. (2006). A model incorporating the rationale and purpose for conducting mixed-methods research in special education and beyond. Learning Disabilities: A Contemporary Journal, 4(1), 67-100.

Cook, T. D., \& Reichardt, C. S. (Eds.). (1979). Qualitative and quantitative methods in evaluation. Beverly Hills, CA: Sage.

Coxon, A. P. (2005). Integrating qualitative and quantitative data: What does the user need? Forum: Qualitative Social Research (FQS), 6(2). Retrieved May 2005 from http://www.qualitative-research.net/fqs-texte/ 2-05/05-2-40-e.htm\#lit

Creswell, J. W. (1999). Mixed-method research: Introduction and application (pp. 455-472). In G. J. Cizek (Ed.), Handbook of educational policy. New York: Academic Press.

Creswell, J. W. (2003). Research design: Qualitative, quantitative and mixed methods approaches (2nd ed.). Thousand Oaks, CA: Sage.

Creswell, J. W., \& Plano Clark, V. L. (2007). Designing and conducting mixed methods research. Thousand Oaks, CA: Sage.

Creswell, J. W., Tashakkori, A., Jensen, K. D., \& Shapley, K. L. (2003). Teaching mixed methods research: Practices, dilemmas, and challenges (pp. 619-638). In A. Tashakkori \& C. Teddlie (Eds.), Handbook of mixed methods in social \& behavioral research. Thousand Oaks, CA: Sage.

Datta, L. (1994). Paradigm wars: A basis for peaceful co-existence and beyond. In C. S. Reichardt \& S. F. Rallis (Eds.), The qualitative-quantitative debate: New perspectives (pp. 53-70). San Francisco: Jossey-Bass.

Denzin, N. K. (1970). Strategies of multiple triangulation (pp. 297-313). In N. K. Denzin (Ed.), The research act in sociology: A theoretical introduction to sociological method. New York: McGraw-Hill.

Giddings, L. S. (2006). Mixed-methods research: Positivism dressed in drag? Journal of Research in Nursing, 11(3), 195-203.

Greene, J. C. (2008). Is mixed methods social inquiry a distinctive methodology? Journal of Mixed Methods Research, 2(1), 7-22.

Greene. J. C., Benjamin, L., \& Goodyear, L. (2001). The merits of mixing methods in evaluation. Evaluation, $7(1), 25-44$.

Greene. J. C., Caracelli, V. J., \& Graham, W. F. (1989). Toward a conceptual framework for mixed-method evaluation designs. Educational Evaluation and Policy Analysis, 11, 255-274.

Greene, J. C., Kreider, H., \& Mayer, E. (2005). Combining qualitative and quantitative methods in social inquiry (pp. 274-281). In B. Somekh \& C. Lewin (Eds.), Research methods in the social sciences. London: Sage.

Gorard, S. (with Taylor, C.). (2004). Combining methods in educational and social research. Maidenhead: Open University Press.

Guignon, C. B. (1991). Pragmatism or hermeneutics? Epistemology after foundationalism. In D. R. Hiley, J. F. Boham, \& R. Shusterman (Eds.), The interpretive turn: Philosophy, science, culture (pp. 81-101). Ithaca: Cornell University Press. 
Hammersley, M. (1989). The dilemma of qualitative method: Herbert Blumer and the Chicago tradition. London: Routledge.

Hammersley, M. (1992). What's wrong with ethnography? London: Routledge.

Hammersley, M. (2005). What can the literature on communities of practice tell us about educational research? Reflections on some recent proposals. International Journal of Research and Method in Education, 28(1), 5-21.

Hardy, M. A., \& Bryman, A. (Eds.). (2004). Handbook of data analysis. London: Sage.

Harvey, L. (1987). Myths of the Chicago school. Aldershot: Gower.

Hodkinson, P. (2004). Research as a form of work: Expertise, community and methodological objectivity. British Educational Research Journal, 30(1), 9-26.

Holmes, C. (2006, July 10-12). Mixed(up) methods, methodology and interpretive frameworks. Paper presented at the Mixed Methods Conference, Cambridge.

Jick, T. D. (1979). Mixing qualitative and quantitative methods: Triangulation in action. Administrative Science Quarterly, 24, 602-611.

Johnson-Lenz, P., \& Johnson-Lenz, T. (1999). Awaking technology. Retrieved November 30, 2007, from http://www.co-i-1.com/coil/knowledge-garden/cop/definitions.shtml

Johnson, R. B., \& Onwuegbuzie, A. J. (2004). Mixed methods research: A research paradigm whose time has come. Educational Researcher, 33(7), 14-26.

Johnson, R. B., Onwuegbuzie, A. J., \& Turner, L. A. (2007). Toward a definition of mixed methods research. Journal of Mixed Methods Research, 1(2), 112-133.

Kuhn, T. S. (1970). The structure of scientific revolutions (2nd ed.). Chicago: University of Chicago Press. (First published 1962)

Lasswell, H. D. (1961). The qualitative and quantitative in political and legal analysis. In D. Lerner (Ed.), Quantity and quality: The Hayden colloquium on scientific method and concept. New York: The Free Press of Glencoe.

Lave, J., \& Wenger, E. (1991). Situated learning_Legitimate peripheral participation. Cambridge: Cambridge University Press.

Layder, D. (1993). New strategies in social research. Cambridge: Polity Press.

Layder, D. (1998). Sociological practice: Linking theory and social research. London: Sage.

Masterman, M. (1970). The nature of a paradigm. In I. Lakatos \& A. Musgrave (Eds.), Criticism and the growth of knowledge. Cambridge: Cambridge University Press.

Maxcy, S. J. (2003). Pragmatic threads in mixed methods research in the social sciences: The search for multiple modes of inquiry and the end of the philosophy of formalism (pp. 51-90). In A. Tashakkori \& C. Teddlie (Eds.), Handbook of mixed methods in social \& behavioral research. Thousand Oaks, CA: Sage.

Mayo, E. (2003). The human problems of an industrial civilization. London: Routledge. (First published 1933 by Macmillan, New York)

Meyer, J. (2005). Health research. In B. Somekh \& C. Lewin (Eds.), Research methods in the social sciences (pp. 8-9). London: Sage.

Mitchell, J., Wood, S., \& Young, S. (2001). Communities of practice: Reshaping professional practice and improving organisational productivity in the vocational education and training sector. Melbourne: Australian National Training Authority.

Morgan, D. L. (2007). Paradigms lost and pragmatism regained: Methodological implications of combining qualitative and quantitative methods. Journal of Mixed Methods Research, 1(1), 48-76.

Morse, J. (2003). Principles of mixed methods and multimethod research design (pp. 189-208). In A. Tashakkori \& C. Teddlie (Eds.), Handbook of mixed methods in social \& behavioral research. Thousand Oaks, CA: Sage.

Onwuegbuzie, A. J., \& Leech, N. L. (2005). On becoming a pragmatic researcher: The importance of combining quantitative and qualitative research methodologies. International Journal of Social Research Methodology, $8(5), 357-387$.

Pring, R. (2000). Philosophy of educational research. London: Continuum.

Rallis, S. F., \& Rossman, G. B. (2003). Mixed methods in evaluation contexts: A pragmatic framework (pp. 491-512). In A. Tashakkori \& C. Teddlie (Eds.), Handbook of mixed methods in social \& behavioral research. Thousand Oaks, CA: Sage. 
Reichardt, C. S., \& Rallis, S. F. (1994). The qualitative-quantitative debate: New perspectives. New Directions for Program Evaluation, 61, 1-98.

Rocco, T. S., Bliss, L. A., Gallagher, S., \& Perez-Prado, A. (2003). Taking the next step: Mixed methods research in organizational systems. Information Technology, Learning and Performance Journal, 21(1), 19-29.

Roethlisberger, F. J., \& Dickson, W. J. (2003). Management and the worker. London: Routledge (First published 1939 by Harvard University Press, Cambridge, MA).

Rorty, R. (1982). Consequences of pragmatism. Minneapolis: University of Minnesota Press.

Rorty, R. (1991). Objectivity, relativism and truth. In Philosophical papers (Vol. 1). Cambridge: Cambridge University Press.

Silverman, D. (1985). Qualitative methodology and sociology: Describing the social world. Aldershot: Gower.

Silverman, D. (2000). Doing qualitative research: A practical handbook. London: Sage.

Somekh, B. (2005). Educational research. In B. Somekh \& C. Lewin (Eds.), Research methods in the social sciences (pp. 7-8). London: Sage.

Tashakkori, A., \& Creswell, J. W. (2007a). The new era of mixed methods. Journal of Mixed Methods Research, 1(1), 3-7.

Tashakkori, A., \& Creswell, J. W. (2007b). Exploring the nature of research questions in mixed methods research. Journal of Mixed Methods Research, 1(3), 207-211.

Tashakkori, A., \& Teddlie, C. (1998). Mixed methodology: Combining qualitative and quantitative approaches. Thousand Oaks, CA: Sage.

Tashakkori, A., \& Teddlie, C. (Eds.). (2003). Handbook of mixed methods in social \& behavioral research. Thousand Oaks, CA: Sage.

Webb, E. J., Campbell, D. T., Schwartz, R. D., \& Sechrest, L. (1966). Unobtrusive measures: Non-reactive research in the social sciences. Chicago: Rand McNally.

Wenger, E. (1998a). Communities of practice: Learning as a social system. Systems Thinker, 9(5), 1-8. Retrieved November 30, 2007, from http://www.co-i-1.com/coil/knowledge-garden/cop/lss.shtml

Wenger, E. (1998b). Communities of practice: Learning, meaning, and identity. Cambridge: Cambridge University Press.

Wenger, E., \& Snyder, W. M. (2000). Communities of practice: The organizational frontier. Harvard Business Review, 78(1), 139-145. 